\title{
MUDANÇAS NA ULTRA-ESTRUTURA DA PAREDE CELULAR DE MANGAS 'TOMMY ATKINS' TRATADAS COM CLORETO DE CÁLCIO NA PRÉ-COLHEITA'
}

\author{
REGINA MARTA EVANGELISTA², ADIMILSON BOSCO CHITARRA ${ }^{3}$, MARIA ISABEL FERNANDES CHITARRA ${ }^{3}$
}

\begin{abstract}
RESUMO - Mangas ‘Tommy Atkins' produzidas na região de Ibirá, São Paulo, foram pulverizadas na pré-colheita com cloreto de cálcio, nas concentrações de $0,0 \%, 2,5 \%$ e 5,0\%, em três épocas de seu desenvolvimento ( $40 ; 60$ e 90 dias após a floração) a fim de verificar a influência do cálcio na estrutura da parede celular destes frutos através de microscopia eletrônica de transmissão, imediatamente após a colheita e depois de 35 dias de armazenamento. Para fixar o material da polpa, utilizou-se metodologia descrita por Jacob e Gowanlock (1995). Nas condições experimentais, verificou-se que os frutos do tratamento-controle (sem cloreto de cálcio), no dia da colheita, já apresentavam desestruturação da parede celular e dissolução da lamela média (LM). A degradação da parede celular ocorre inicialmente na LM, levando à formação de espaços vazios bastante distintos, apresentando uma dissolução ainda maior, com o armazenamento prolongado (35 dias). Os frutos tratados com cloreto de cálcio a 5,0\% apresentaram uma LM bem definida e ausência de espaços vazios, mesmo após o armazenamento, mostrando ser uma concentração efetiva na preservação da lamela média.
\end{abstract}

Termos para indexação: manga; amadurecimento; lamela média; armazenamento.

\section{ULTRASTRUCTURAL CHANGES IN THE CELL WALL OF MANGO 'TOMMY ATKINS' TREATED WITH CALCIUM CHLORIDE AT PRE-HARVEST TIME}

\begin{abstract}
Mango 'Tommy Atkins ' produced in Ibirá, São Paulo, was treated at preharvest time with concentrations of 0,0\%, 2,5\% and 5,0\% calcium chloride at three times of its development (40,60 and 90 days after antesis) in order to identify the influence of calcium on the structure of the cell wall, by using transmission electron microscopy (TEM), immediately after the harvest and at 35 days of storage. The methodology described by Jacob and Gowanlock (1995) was used to fix the pulp material. It was observed that untreated fruits (without calcium chloride) showed desintegration of the cell wall and breakup of the middle lamella (LM) at the harvest time. The degradation of the LM site starts with the formation of quite different empty spaces, whose breakups are larger when prolonging storage for 35 days. The treated fruits with calcium chloride at 5,0\% presented a defined LM and absence of empty spaces, even after storage. The application of calcium chloride at 5,0\% was effective to preserve the middle lamella structure.
\end{abstract}

Index terms: mango; ripening; middle lamella; storage.

A manga (Mangifera indica L.) é uma fruta tropical de grande importância econômica, sendo o segundo fruto tropical mais importante cultivado no mundo. Entretanto, é uma fruta altamente perecível, e sua distribuição para centros distantes é limitada pela curta vida pós-colheita à temperatura ambiente (Yuen et al., 1993).

A notável habilidade dos tratamentos com cálcio em estender a vida pós-colheita de muitos frutos, incluindo mangas, tem sido bastante estudada (Yuen et al., 1993). Tirmazi e Wills (1981) e Wills et al. (1988) estabeleceram que a aplicação a vácuo de cloreto de cálcio a $4 \%$ foi efetivo em retardar o amadurecimento de manga. Yuen et al. (1993) também verificaram que infiltração de cálcio a vácuo nas concentrações de 2; 4; 6 e $8 \%$ atrasaram o amaciamento de mangas 'Kensington Pride' por 8 a 12 dias a $20^{\circ} \mathrm{C}$.

Fotomicrografias de elétrons mostram que o cálcio é efetivo em preservar a parede celular e, em particular, a região da lamela média, que é rica em poliuronídeos. Parece servir como um agente de ligação intermolecular, que estabiliza o complexo pectina-proteína da lamela média. Estudos prévios das mudanças composicionais da parede celular de maçãs indicam que um aumento no teor de poliuronídeos solúveis ocorre quando o tecido do fruto torna-se macio. Os íons cálcio inibem o processo de solubilização desses poliuronídeos, reduzindo com isso a taxa de amaciamento dos frutos (Glenn, Reddy e Poovaiah, 1988 ).

Através de microscopia eletrônica de transmissão (TEM), é possível observar as modificações na lamela média e na parede celular, que ocorrem durante o amadurecimento dos frutos. Glenn, Reddy e Poovaiah (1988) e Glenn e Poovaiah (1990) utilizaram microscopia eletrônica de transmissão para observar a parede celular de maçãs tratadas com cálcio. Uma visível degradação ocorreu na lamela média dos frutos-controle. Em algumas células, a lamela média apresentou pontos brancos, sugerindo a extensa degradação que ocorreu, enquanto, em outras regiões, as quebras foram menores. A modificação na orientação das microfibrilas era visível na região da parede celular 
adjacente à lamela média dos frutos-controle. A lamela média dos frutos tratados permaneceu escura, indicando a presença de material intercelular.

Ben-Arie et al. (1979) avaliaram as modificações em maçãs e peras e observaram que os frutos imaturos (firmes) mostram a lamela média como uma massa compacta e escura. A parede celular dos frutos macios mostra quebra e dispersão das fibras, formação de espaços vazios e a região da lamela média desintegra-se.

Em mangas, existe um trabalho utilizando microscopia eletrônica de transmissão (TEM) onde se avaliou a parede celular destes frutos tratados com água quente, porém não existe nenhum trabalho relacionando parede celular e aplicação de cloreto de cálcio. Assim sendo, objetivou-se, neste trabalho, verificar as modificações na parede celular de mangas tratadas na pré-colheita com cloreto de cálcio, através da microscopia eletrônica de transmissão.

$\mathrm{O}$ experimento foi conduzido com mangas cultivar Tommy Atkins, produzidas na região de Ibirá, oeste do Estado de São Paulo. Esta região apresenta temperatura média anual de $23^{\circ} \mathrm{C}$ e precipitação pluviométrica média anual de $1300 \mathrm{~mm}$.

Foram utilizadas plantas em produção, com 18 anos de idade, cultivadas em espaçamento de $8 \mathrm{~m}$ por $7 \mathrm{~m}$. Em uma única fileira deste pomar contendo vinte e uma plantas, o experimento foi conduzido adotando-se aplicações nutritivas por meio de pulverizações de $0 \%, 2,5 \%$ e 5,0\%. Cada tratamento foi aplicado em 5 plantas, com um intervalo de três plantas entre os mesmos. A primeira aplicação foi realizada 40 dias após a floração, a segunda 60 dias e a terceira 90 dias após a floração.

Os frutos foram colhidos manualmente, dia 6 de dezembro de 1995, usando como parâmetro látex claro (transparente) e polpa amarelada, levados para o barracão onde foram imersos por 5 minutos em um tanque com água à temperatura ambiente $\left(26^{\circ} \mathrm{C}\right)$ contendo Sportak $(0,25 \%)$. Após a imersão, os frutos foram secos ao ar e classificados de acordo com seus tamanhos do tipo 8; 9 e 10 frutos em caixas do tipo exportação de $4,5 \mathrm{~kg}$, classificados por diferença de peso. No experimento, foram utilizados frutos dos tamanhos $8 ; 9 \mathrm{e} 10$ (n ${ }^{\circ}$ de frutos por caixa). Os frutos foram transportados no mesmo dia para o Laboratório de Bioquímica e Fisiologia Pós-colheita de Frutos e Hortaliças, do Departamento de Ciência dos Alimentos, da Universidade Federal de Lavras- UFLA .

As polpas dos frutos dos três tratamentos foram cortadas em pequenos discos $\left(2 \mathrm{~mm}^{2}\right)$ no dia em que foram colhidos e após 35 dias de armazenamento a $10 \pm 1^{\circ} \mathrm{C}$ e $80-90 \%$ UR.

Utilizou-se a metodologia descrita por Jacobi e Gowanlock (1995) com as seguintes modificações: a) Para a fixação, os discos de manga foram imersos em glutaraldeído a $2,5 \%$, paraformaldeído a $2 \%$, tamponado em cacodilato de sódio a 0,05 M, por 19 horas; b) Em seguida, efetuaram-se quatro lavagens com o tampão cacodilato de sódio a $0,05 \mathrm{M}$, em cujo tampão os discos ficavam imersos por 15 minutos; c) $\mathrm{O}$ tecido foi pós-fixado em tetróxido de ósmio a 1\%, por 3 horas e, em seguida, lavado com quatro porções de água destilada, colocado em acetato de uranila a $0,5 \%$, por uma noite; d) Após este tratamento, o tecido foi desidratado em acetona a 30\%, 50\%, $70 \%, 90 \%$ e $100 \%$; e) Após a desidratação, foi embebido em resina Epon mais acetona (1:1) por três horas e meia, Epon mais acetona (2:1) por 3 horas, Epon puro por uma noite a $60^{\circ} \mathrm{C}$, por 48 horas. Após o material se tornar firme, fez-se o corte em seções ultrafinas, utilizando um micrótomo-Reichert Jung. As seções foram coradas com acetato de uranila e levadas ao microscópio eletrônico de transmissão- Electron Microscope EM-301 Philips, para serem fotografadas.

A parede celular (PC) dos frutos-controle (sem aplicação de cloreto de cálcio), no dia da colheita, mostra que a maioria apresenta desestruturação da parede celular e dissolução da lamela média (LM) (Figuras 1 e 2). A degradação da parede celular ocorre inicialmente na lamela média, que é rica em protopectina, levando à formação de espaços vazios bastante visíveis. Uma degradação da lamela média e do material fibrilar também foi observada por Gutiérrez et al. (1992) com cherimoyas maduras, utilizando microscopia eletrônica. Esses autores observaram que, nos frutos maduros, ocorria uma desintegração da parede celular, degradação do amido e uma desorganização das membranas.

Quando os frutos foram tratados com cloreto de cálcio, nas duas concentrações utilizadas (2,5 e 5,0\%), no dia da colheita, notou-se que o cálcio foi efetivo na preservação da parede celular, em particular a região da lamela média, rica em poliuronídeos (Figuras 3 a 6). Quando se utilizou a concentração de 5,0\%, verificou-se que as células estavam unidas e a parede celular intacta. A lamela média dos frutos tratados com cálcio permaneceu escura, indicando presença de material intercelular (Figuras 3 a $6)$.

Resultados semelhantes foram observados por Glenn, Reddy e Poovaiah (1988) em maçãs 'Golden Delicious'. O cálcio foi efetivo, mantendo a estrutura da parede celular, particularmente a lamela média. $O$ cálcio parece servir como um agente de ligação intermolecular, estabilizando o complexo pectina-proteína da lamela média. Estudos com parede celular de maçãs indicam que ocorre um aumento nos poliuronídeos solúveis com o amaciamento da polpa. O cálcio inibe este processo de solubilização e reduz a taxa de amaciamento do tecido (Glenn e Poovaiah, 1990). O cálcio preservou a integridade estrutural da parede celular e manteve a coesividade das células. Hudson e Buescher (1985) sugerem que o cálcio reduz o amaciamento dos tecidos, pois protege as macromoléculas de pectina da desmetilação. Sams e Conway (1984) reforçam que a manutenção da integridade da parede celular e da firmeza de frutos tratados com cálcio é o resultado da redução da despolimerização devido às ligações do $\mathrm{Ca}^{+2}$ com os grupos carboxílicos livres dos polímeros de poligalacturonato da parede celular e lamela média. Evangelista, Chitarra e Chitarra (2000) observaram uma manutenção da firmeza de mangas 'Tommy Atkins' tratadas com cloreto cálcio a 2,5 e 5,0\%, e verificaram que quanto maior a concentração aplicada, mais firmes permaneceram os frutos, embora tenha sido observada uma diminuição da textura durante o armazenamento por 35 dias, nos tratamento utilizados.

As Figuras de 7 a 12 são da parede celular dos frutos após 35 dias de armazenamento a $10 \pm 1{ }^{\circ} \mathrm{C}$ e $80-90 \%$ UR. Os frutos-controle apresentaram uma maior dissolução da parede celular (Figuras 7 e 8) onde as fibras perderam a orientação. A parede celular dos frutos tratados com cloreto de cálcio a $2,5 \%$, após 35 dias de armazenamento, apresentou regiões totalmente preservadas (Figura 10), em contraste com outras onde a desestruturação ocorreu (Figura 9). Resultados semelhantes foram observados por Glenn e Poovaiah (1990) em algumas células, onde a região da lamela média apresentava grandes 

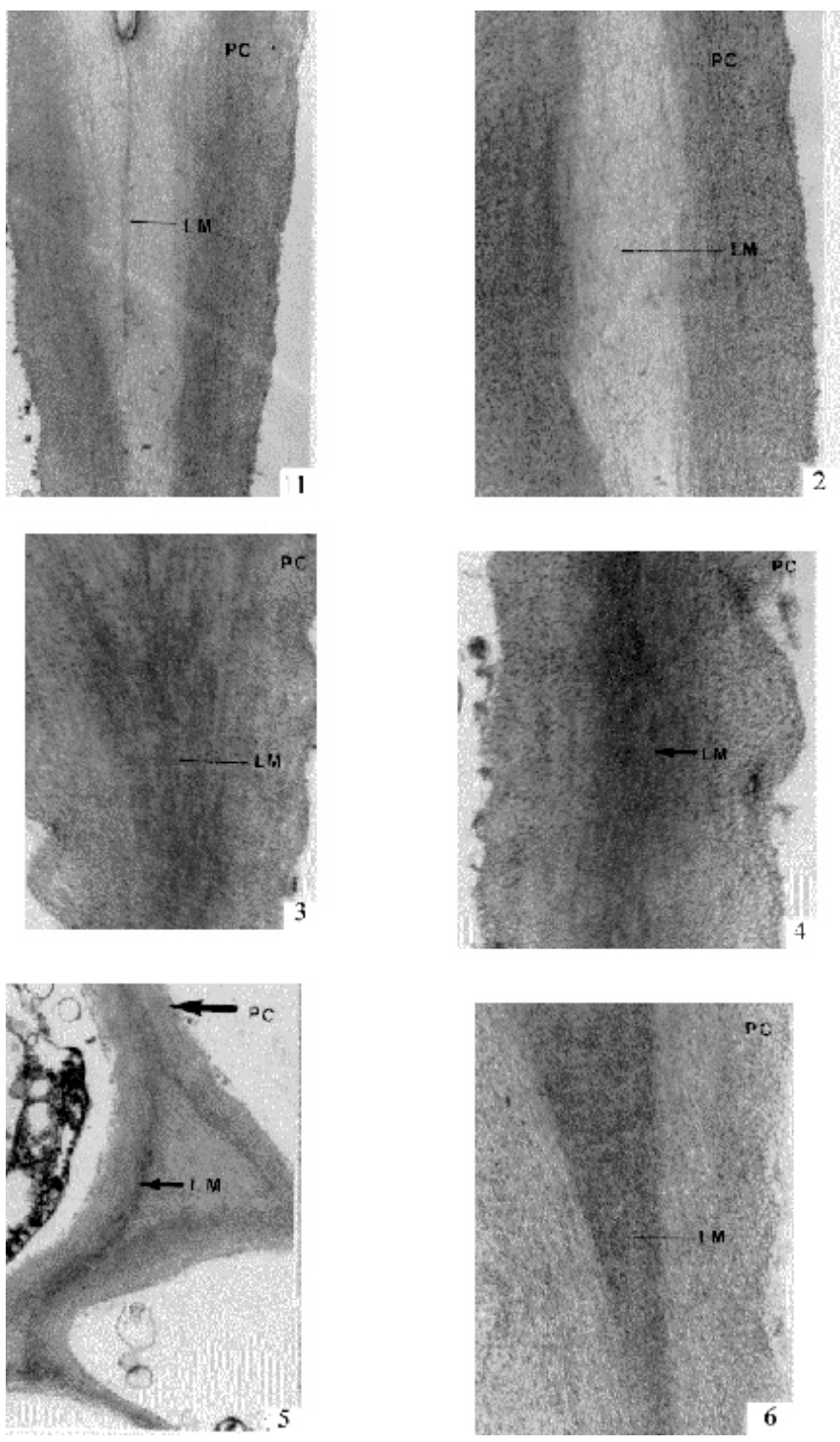

FIGURAS 1 a 6 - Microscopia eletrônica de transmissão da parede celular dos frutos-controle (não tratados com cálcio- Fig. 1 e 2), tratados com $\mathrm{CaCl}_{2}$ a 2,5\% (Fig. 2 e 3) e a 5,0\% (Fig. 5 e 6), no dia em que foram colhidos.

espaços vazios, sugerindo que uma grande dissolução tinha ocorrido; entretanto, em outras regiões, observou-se menor desestruturação.

No tratamento com cloreto de cálcio a 5,0\%, a lamela média permaneceu escura, indicando presença de material intercelular (Figuras 11 e 12).

Assim sendo, conclui-se que, através da microscopia eletrônica de transmissão, se verificou que os frutos tratados com cloreto de cálcio a 5,0\% apresentaram lamela média bem definida (escura) e ausência de espaços vazios, mesmo após 35 dias de armazenamento.

A microscopia eletrônica de transmissão detectou que a concentração de cloreto de cálcio a $2,5 \%$ não se apresentou consistente quanto à preservação da lamela média.

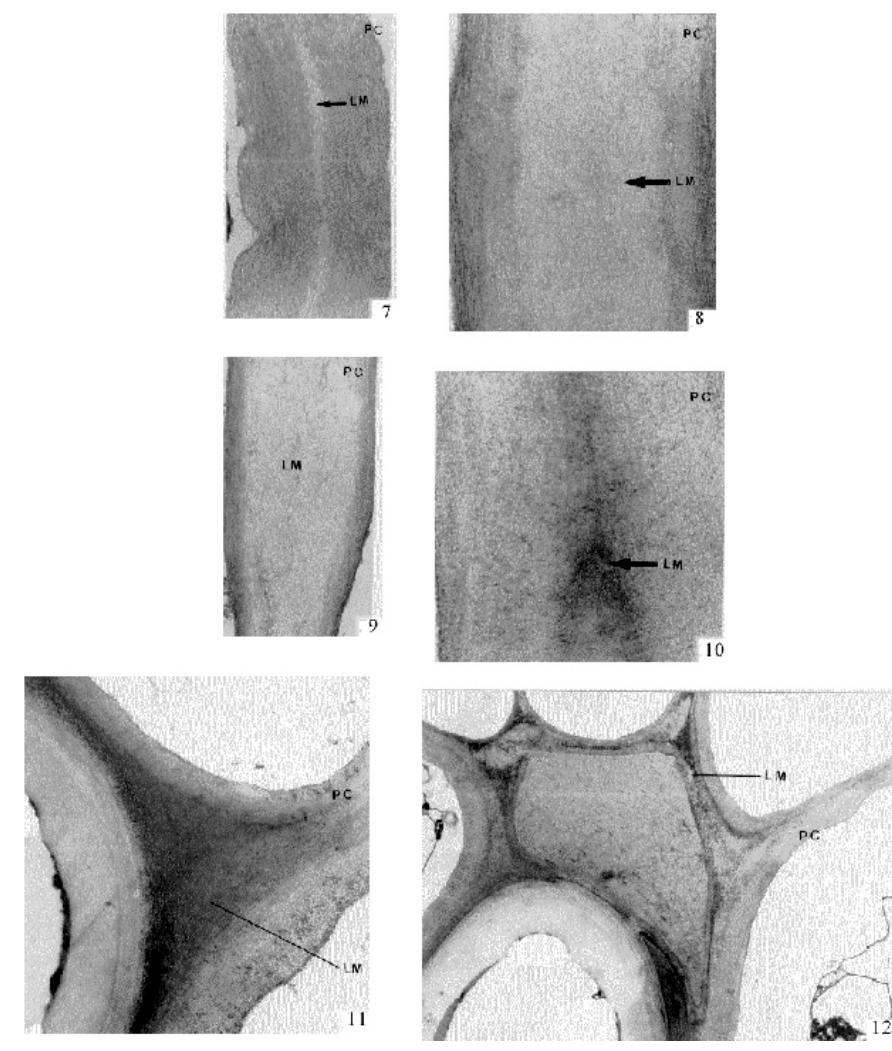

FIGURAS 7 a 12 - Microscopia eletrônica de transmissão da parede celular de frutos-controle (não tratados com $\mathrm{CaCl}_{2}$ - Fig 7 e 8) tratados com $\mathrm{CaCl}_{2}$ a 2,5\% (Fig. 9 e 10) e 5,0\% (Fig 11 e 12) após 35 dias de armazenamento a $10 \pm 1^{\circ} \mathrm{C}$ e $80-90 \%$ UR.

\section{REFERÊNCIAS BIBLIOGRÁFICAS}

BEN-ARIE, R.; KISLEU, N.; FRENKEL, C. Ultrastructural changes in the cell wall of ripening apple and pear fruit. Plant Physiology, Rockville Pike, v.64, n.2, p.197-202,1979.

EVANGELISTA, R.M.; CHITARRA, A. B.; CHITARRA, M.I.F. Influência da aplicação pré-colheita de cálcio na textura e na atividade das enzimas poligalacturonse, pectinametilesterase e $\beta$-galactosidase de mangas 'Tommy Atkins' armazenadas sob refrigeração. Ciência e Agrotecnologia , Lavras, v.24 (edição especial), p.174-181, dez., 2000.

GLENN, G. M.; POOVAIAH, B.W. Calcium mediated postharvest changes in texture and cell wall struture and composition in 'Golden Delicious' apples. Journal of the American Society for Horticultural Science, Alexandria, VA, v.115, n.6, p.962-968, 1990.

GLENN, G.M.; REDDY, A.S.N., POOVAIAH, B.W. Effect of calcium cell wall struture protein phosphorilation and protein profile in senecing apples. Plant and Cell Physiology, Kamikyoku, v.29, n.4, p.565-572, 1988.

GUTIÉRREZ, M.; SOLA, M.D.M.; PASCUAL, L .et al. Ultrastructural changes in cherimoya fruti injuried by chilling. Food Struture, v.11, n.4, p. 323-332, 1992. 
HUDSON, J.M.; BUESCHER, R.W. Pectic substances and firmness of cucumber pickles as influenced by $\mathrm{CaCl}_{2}, \mathrm{NaCl}$ and brine storage. Journal of Food Biochemistry, Trumbull, v.9, p.211$229,1985$.

JACOBI, K.K .; GOWANLOCK, D. Ultrastructural studies of 'Kensigton' mango (Mangifera indica Linn.) heat injuries. HortScience, Alexandria, VA,v.30, n.1, p.102-103, feb., 1995.

SAMS, C.E.; CONWAY, W.S. Effect of calcium infitration on ethylene production, respiration rate, soluble poliuronide content, and quality of 'Golden Delicious' apple fruit. Journal of the American Society for Horticultural Science, Alexandria, v.109, n.1,p.53-57, 1984 .
TIRMAZI, S.I.H.; WILLS, R.B.H. Retardation of ripening of mangoes by postharvest application of calcium. Tropical Agriculture, London, v.58, p.137-141, 1981.

WILLS, R.B.H.; YUEN, C.M.C.; LAKSMIS, L.D.S. et al. Effect of calcium infiltration on delayed ripening of three mango cultivars in Indonesia. ASEAN Food Journal, v.4, n.2, p.67-68, 1988.

YUEN, C.M.C.; TAN,S.C.; JOYCE, D. et al. Effect of postharvest calcium and polymeric fimls on ripening and peel injury in Kensigton Pride mango. ASEAN Food Journal, Kuala Lampur, v.8, n.3, p. 110-113, 1993. 